\title{
Constitutive Modeling of High Temperature Uniaxial Creep-Fatigue and Creep-Ratcheting Responses of Alloy 617
}

\section{PVP2013}

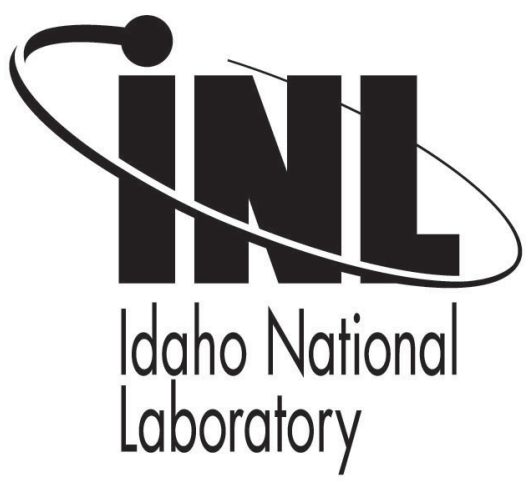

This is a preprint of a paper intended for publication in a journal or proceedings. Since changes may be made before publication, this preprint should not be cited or reproduced without permission of the author. This document was prepared as an account of work sponsored by an agency of the United States Government. Neither the United States Government nor any agency thereof, or any of their employees, makes any warranty, expressed or implied, or assumes any legal liability or responsibility for any third party's use, or the results of such use, of any information, apparatus, product or process disclosed in this report, or represents that its use by such third party would not infringe privately owned rights. The views expressed in this paper are not necessarily those of the United States Government or the sponsoring agency. 
PVP2013-97251

\section{Constitutive Modeling of High Temperature Uniaxial Creep-Fatigue and Creep-Ratcheting Responses of Alloy 617}

\author{
P.G. Pritchard \\ North Carolina State University \\ Raleigh, NC, USA
}

\author{
L. Carroll \\ Idaho National Laboratory \\ Idaho Falls, ID, USA
}

\author{
T. Hassan \\ North Carolina State University \\ Raleigh, NC, USA
}

\begin{abstract}
Inconel Alloy 617 is a high temperature creep and corrosion resistant alloy and is a leading candidate for use in Intermediate Heat Exchangers (IHX) of the Next Generation Nuclear Plants (NGNP). The IHX of the NGNP is expected to experience operating temperatures in the range of $800^{\circ}-950^{\circ} \mathrm{C}$, which is in the creep regime of Alloy 617. A broad set of uniaxial, low-cycle fatigue, fatigue-creep, ratcheting, and ratcheting-creep experiments are conducted in order to study the fatigue and ratcheting responses, and their interactions with the creep response at high temperatures. A unified constitutive model developed at North Carolina State University is used to simulate these experimental responses. The model is developed based on the Chaboche viscoplastic model framework. It includes cyclic hardening/softening, strain rate dependence, strain range dependence, static and dynamic recovery modeling features. For simulation of the alloy 617 responses, new techniques of model parameter determination are developed for optimized simulations. This paper compares the experimental responses and model simulations for demonstrating the strengths and shortcomings of the model.
\end{abstract}

\section{Nomenclature}

$C_{i} \quad$ Kinematic hardening parameter

$C_{i}{ }^{A S} \quad$ Kinematic hardening evolution parameter

$D_{y i} \quad$ Kinematic hardening evolution rate parameter

$D_{C i} \quad$ Kinematic hardening evolution rate parameter

E Young's modulus

$H \quad$ Heaviside function

I Identity tensor
J( ) Second invariant

$K \quad$ Rate dependent parameter

LCF Low cycle fatigue

$\mathrm{N} \quad$ Number of cycles

$R \quad$ Isotropic hardening parameter

a Deviator of back stress

$\boldsymbol{a}_{C i} \quad$ Kinematic hardening evolution parameter

$\mathbf{a}_{i} \quad$ Decomposed deviator of back stress

$a_{\gamma i} \quad$ Kinematic hardening evolution parameter

$b \quad$ Isotropic hardening rate parameter

$b_{C i} \quad$ Kinematic hardening evolution parameter

$b_{i} \quad$ Kinematic hardening static recovery parameter

$b_{\gamma i} \quad$ Kinematic hardening evolution parameter

$c_{1 R} \quad$ Isotropic hardening evolution parameter

$C_{C i} \quad$ Kinematic hardening evolution parameter

$C_{y i} \quad$ Kinematic hardening evolution parameter

$g \quad$ Strain memory surface

$m_{s r} \quad$ Strain memory surface radius evolution parameter

n Normal to viscoplastic potential surface

n* Normal to strain memory surface

$\mathrm{p} \quad$ Cumulative inelastic strain

$q \quad$ Radius of strain memory surface

$r$

$\mathbf{S}$

$t$

tr

$\boldsymbol{\alpha}$

$\alpha_{b}$

$\gamma_{i}{ }_{i}^{A S}$

$\Delta \varepsilon$

$\boldsymbol{\varepsilon}^{\mathbf{e}} \quad$ Elastic strain tensor 
Inelastic strain tensor

Strain memory surface radius evolution parameter

Poisson's ratio

Strain memory surface radius evolution parameter

Stress tensor

Yield stress

Differentiation with respect to time

\section{Introduction}

Alloy 617 is a high temperature creep and corrosion resistant alloy that is a leading candidate for use in the Intermediate Heat Exchanger (IHX) of the Next Generation Nuclear Plant (NGNP). The IHX has an expected operating temperature in the range of $800^{\circ}-950^{\circ} \mathrm{C}$, which is within the creep regime of alloy 617. During start-up and shut-down of the reactor the IHX component will experience thermomechanical fatigue (TMF) loading. Furthermore, under operating conditions, the IHX will be subject to a complex state of stress and strain; the design for which will require a broad understanding of the mechanical behavior of alloy 617 at elevated temperatures. Very few investigations have been made into the low cycle fatigue and fatigue-creep response of alloy 617. Moreover, the past experiments were performed under strain-controlled loading [1-8]. Currently, according to the author's knowledge, no stress-controlled, high temperature, low cycle fatigue loading responses of alloy 617 are available in the literature. This investigation performs a broad set of stresscontrolled and strain-controlled low cycle fatigue experiments to understand the low cycle fatigue and ratcheting failure responses of alloy 617 at high temperatures.

In addition, these fatigue-creep and ratcheting-creep responses are essential in developing an experimentally validated unified constitutive model (UCM). The UCM needs to be robust enough to be able to simulate the whole set of alloy 617 responses with reasonable accuracy. Such a UCM can be used in the design of IHX components using ASME design by analysis. The main objective of this study is to develop a systematic set of alloy 617 fatigue, fatigue-creep, ratcheting, and ratcheting-creep responses. Subsequently, an experimentally validated UCM will be developed to simulate the whole set of alloy 617 responses with reasonable accuracy for design applications.

\section{Experimental Study}

To characterize alloy 617's response under low cycle fatigue (LCF) loading, which includes, fatigue, fatigue-creep, ratcheting and ratcheting-creep, a broad set of experiments have been conducted. Six wave forms have been prescribed as shown in Figs. 1a-f. The two strain-controlled waveforms, UF1 and UF2 (Figs. 1a-b), capture the low cycle fatigue and low cycle fatigue-creep responses, respectively. Waveforms UR1 and UR3 (Figs. 1c and 1e) capture the ratcheting response while waveforms UR2 and UR4 (Figs. 1d and 1f) capture the ratcheting-creep response. Previous works have shown that a tensile peak hold under strain controlled loading is more prone to fatigue crack initiation and failure than either a compressive peak hold or both tensile and compressive peak holds together [7-8]. Therefore, only tension peak holds were considered in this investigation. However, it should be noted that a very recent work has shown that this is not the case for fatigue-creep loadings performed at a strain range of $0.3 \%$ [5]. Lastly, it should be noted that in many of the tests a few lower amplitude cycles of increasing magnitude were prescribed. These prevent an initial overshoot of the target strain or stress in high temperature experiments.

At high temperatures, alloy 617 behaves as a viscoplastic solid. Therefore, various strain rates, strain ranges, strain holds, and stress holds have been prescribed in order to capture the viscoplastic material response. In total, 34 strain-controlled and 27 stress-controlled tests have been performed. Table $1 \mathrm{a}$ and $1 \mathrm{~b}$ are the test matrices for the strain-controlled and stresscontrolled experiments conducted.

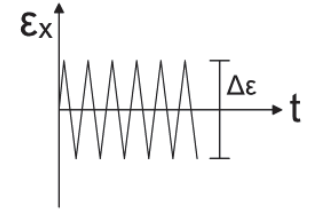

(a) UF1: Fatigue

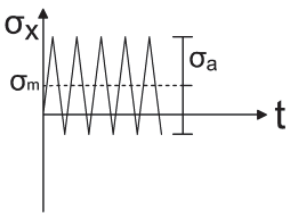

(c) UR1: Ratcheting

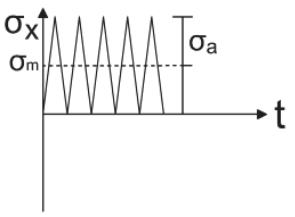

(e) UR3: Ratcheting

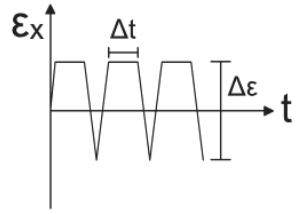

(b) UF2: Fatigue-Creep

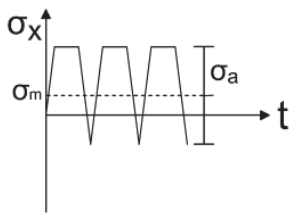

(d) UR2: RatchetingCreep

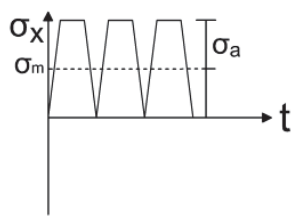

(f) UR4: RatchetingCreep
Fig. 1 Loading Histories Prescribed in the Experiments 
Table 1a: Test matrix of strain-controlled experiments.

\begin{tabular}{ccccc}
\hline $\begin{array}{c}\text { Test } \\
\text { type }\end{array}$ & $\begin{array}{c}\text { No. of } \\
\text { specimens }\end{array}$ & $\begin{array}{c}\text { Temp. } \\
\left({ }^{\circ} \mathbf{C}\right)\end{array}$ & $\begin{array}{c}\text { Strain rate } \\
(\% / \mathbf{s})\end{array}$ & $\begin{array}{c}\text { Strain } \\
\text { range }(\%)\end{array}$ \\
\hline UF1 & 16 & 850,950 & $0.04,0.1$ & $0.4,0.6$ \\
\hline UF1- & 10 & 850,950 & $0.04,0.1$ & $0.3,0.6$, \\
MR* & & 850,950 & $0.04,0.1$ & $0.4,0.6$ \\
\hline UF2 & 8 &
\end{tabular}

* MR indicates multiple strain ranges prescribed in one test with increasing amplitude

Table 1b: Test matrix of stress-controlled experiments.

\begin{tabular}{ccccc}
\hline Test type & $\begin{array}{c}\text { No. of } \\
\text { specimens }\end{array}$ & $\begin{array}{c}\text { Temp. } \\
\left({ }^{\circ} \mathbf{C}\right)\end{array}$ & $\begin{array}{c}\text { Max } \\
\text { Stress } \\
(\mathbf{M P a})\end{array}$ & $\begin{array}{c}\text { Min Stress } \\
(\mathbf{M P a})\end{array}$ \\
\hline UR1 & 9 & 850,950 & $110-230$ & $(-30)-(-55)$ \\
\hline UR2 & 6 & 850,950 & $50-180$ & $(-30)-(-40)$ \\
\hline UR3 & 7 & 850,950 & $110-230$ & 0 \\
\hline UR4 & 5 & 850,950 & $50-180$ & 0 \\
\hline
\end{tabular}

\section{Experimental Responses}

\section{Strain Controlled Experiments}

As mentioned previously, the IHX of NGNP will operate within an expected operation temperature in the range of 800 to $950^{\circ} \mathrm{C}$. In the first step of this study, the material responses are explored at both 850 and $950^{\circ} \mathrm{C}$. As there is a large variation in the hysteretic response between these two temperatures, the material responses at $850^{\circ} \mathrm{C}$ will be presented and discussed first, followed by the responses at $950^{\circ} \mathrm{C}$.

It is noted that at $850^{\circ} \mathrm{C}$ serrated flow is seen in the stressstrain hysteresis loops. As noted in Rao et al, "serrated flow is considered to be one the manifestations of dynamic strain aging" or DSA [8]. Serrated flow is present in every test performed at $850^{\circ} \mathrm{C}$. In the tests performed at the higher strain rate of $0.1 \% / \mathrm{s}$, serrated flow is present throughout the entire test duration (Fig. 2). On the other hand, as shown in Fig. 3, the tests performed at a strain rate of $0.04 \% / \mathrm{s}$, only show serrated flow during the first few cycles. The reduced presence of serrated flow at lower strain rates at $850^{\circ} \mathrm{C}$ is consistent with the findings in Rao et al. [7-8]. Moreover, it is important to note that in all the tests performed at a strain rate of $0.04 \% / \mathrm{s}$ and at $850^{\circ} \mathrm{C}$, the hysteresis loop shape seen in the first few cycles, $8-10$, is significantly different than the shape seen in subsequent cycles (Fig. 3). This change in hysteresis loop shape is independent of the cyclic hardening or softening response. This phenomenon increases the difficulty of creating a uniform set of parameters to represent the material response at $850^{\circ} \mathrm{C}$.

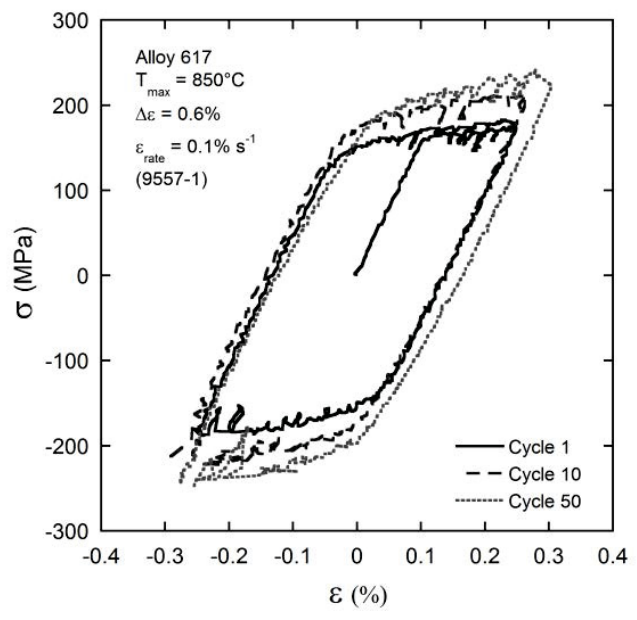

Fig. 2 Alloy 617 hysteresis loops from a UF1 test performed at $850^{\circ} \mathrm{C}$

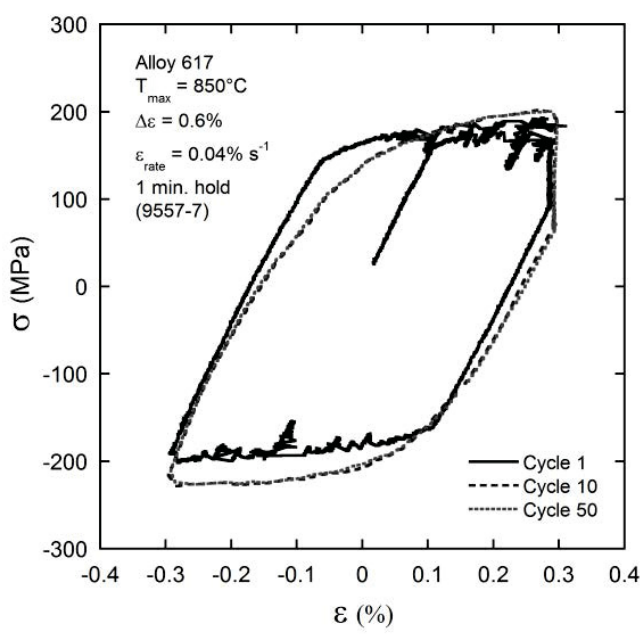

Fig. 3 Alloy 617 hysteresis loop from a UF2 test performed at $850^{\circ} \mathrm{C}$

At $850^{\circ} \mathrm{C}$ cyclic hardening is observed in the initial cycles and subsequently followed by cyclic softening. The cyclic stress amplitude response is shown in Figs. 4-5. In Fig. 4, two uniaxial strain-controlled tests (UF1) are compared; one with a strain rate of $0.1 \% / \mathrm{s}$ and one with a strain rate of $0.04 \% / \mathrm{s}$. In Fig. 5, two uniaxial strain-controlled tests with one minute tension holds (UF2) are compared with both of the aforementioned strain rates. Cyclic hardening occurs for the first 50-75 cycles in the tests performed at a strain rate of $0.1 \% / \mathrm{s}$, while only occurring for $5-10$ cycles in the tests performed at a strain rate of $0.04 \% / \mathrm{s}$. Furthermore, the magnitude of cyclic hardening is most prominent in the tests performed at a strain rate of $0.1 \% / \mathrm{s}$, while it is seen to a lesser degree in the tests performed at the slower strain rate of $0.04 \% / \mathrm{s}$. The degree of cyclic hardening in the initial cycles is 
not affected by the application a tension hold. After the initial cyclic hardening in the UF1 and UF2 tests, a cyclic softening phase begins. The degree of cyclic softening seen is higher in the tests performed at a higher strain rate and also in those performed with a tensile hold.

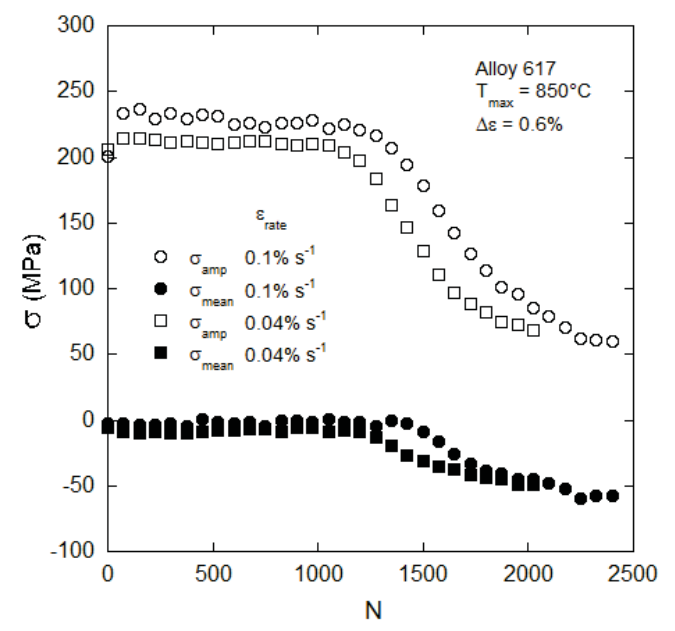

Fig. 4 Stress amplitude and mean of UF1 experiments performed at $850^{\circ} \mathrm{C}$

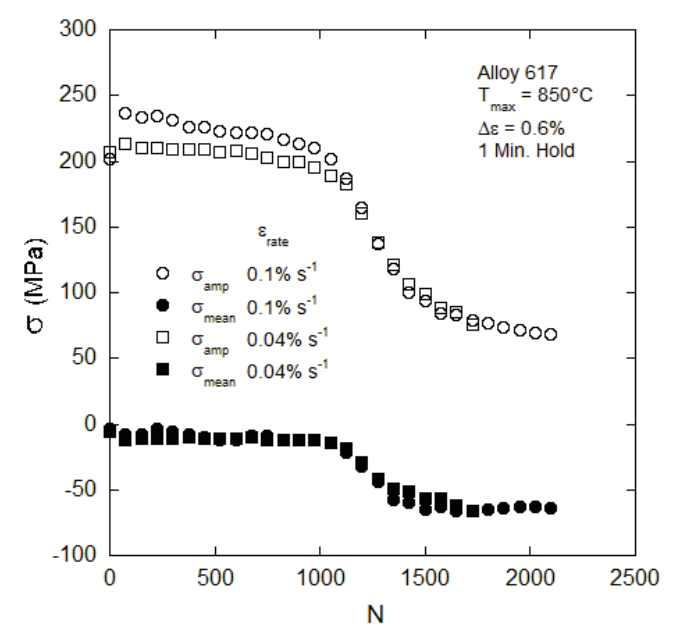

Fig. 5 Stress amplitude and mean of UF2 experiments performed at $850^{\circ} \mathrm{C}$

The current data set of strain-controlled experiments at $950^{\circ} \mathrm{C}$ has been generously supplied by the Idaho National Laboratory. More strain-controlled tests are underway to supplement this data set.

An important difference in the material response between $850^{\circ} \mathrm{C}$ and $950^{\circ} \mathrm{C}$ is the decrease in stress amplitude. The stress amplitude after the initial cyclic hardening in the uniaxial strain-controlled test performed at a strain range of $0.6 \%$, strain rate of $0.1 \% / \mathrm{s}$, and at $850^{\circ} \mathrm{C}$ is $236 \mathrm{MPa}$ (Fig. 4). If the temperature is increased to $950^{\circ} \mathrm{C}$ with the same loading parameters, the stress amplitude, after the initial softening, is $132 \mathrm{MPa}$ (Fig. 7). This is a $44 \%$ decrease in strength. In addition, from a modeling aspect, it is important to note that the complexity of the material response is greater at $950^{\circ} \mathrm{C}$ than at $850^{\circ} \mathrm{C}$.

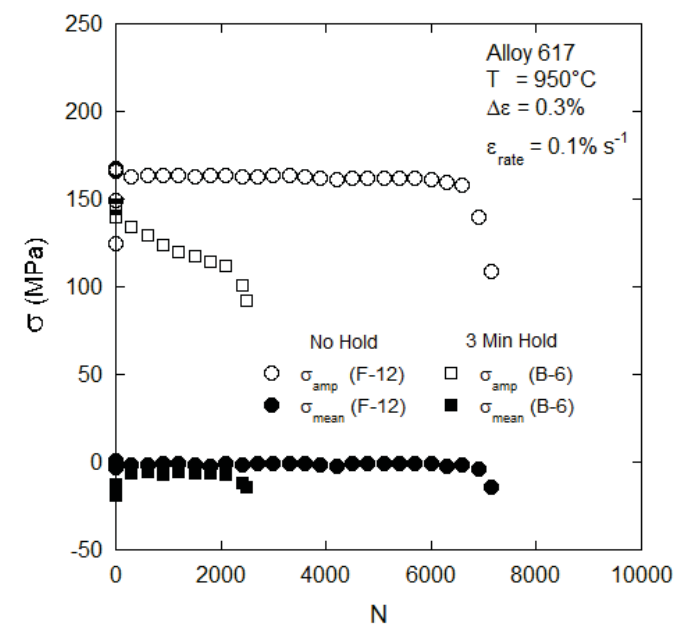

Fig. 6 Stress amplitude $\left(\sigma_{x c}\right)$ and mean $\left(\sigma_{x m}\right)$ in UF1 experiments performed at $950^{\circ} \mathrm{C}$

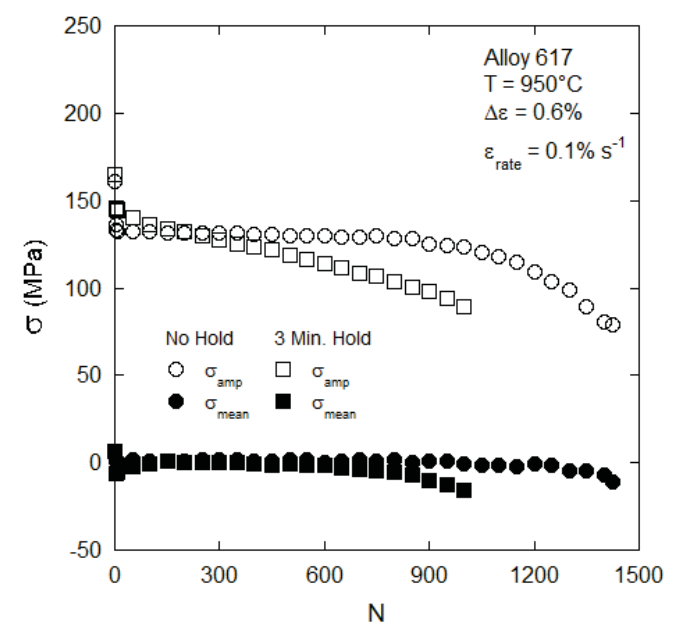

Fig. 7 Stress amplitude $\left(\sigma_{\mathrm{xc}}\right)$ and mean $\left(\sigma_{\mathrm{xm}}\right)$ in UF2 experiments performed at $950^{\circ} \mathrm{C}$

Similar to the response at $850^{\circ} \mathrm{C}$, the application of a tension hold significantly increases cyclic softening under strain-controlled loading (Figs. 6-7). The uniaxial straincontrolled tests performed at strain ranges of $0.3 \%$ and $0.6 \%$ strain ranges do not show cyclic softening for the majority of the cycle life. In contrast the uniaxial strain-controlled test with tension holds show a large degree of cyclic softening at both the $0.3 \%$ and $0.6 \%$ strain ranges $[4,6]$. Furthermore, the 
application of a tension hold at the peak tension strain has a clear impact on the cycle life of the material. As can be seen in Figs. 6 and 7, and as is discussed in Carroll et al. [2], the cycle life is reduced upon the application of tension holds.

Also of interest is the apparent cyclic hardening behavior observed in the first few cycles of the tests performed at $0.3 \%$ compared to the cyclic softening behavior seen in tests performed at larger strain ranges. In Fig. 6, it appears that cyclic hardening occurs during the first few cycles. However, as mentioned previously, a few lower amplitude cycles were initially prescribed to prevent overshooting the target strain. Therefore, the initial increase in stress amplitude observed was due to the increase in the strain amplitude and not to cyclic hardening of the material. Fig. 7 shows the opposite of this, a very quick cyclic softening of the material observed during the initial cycles. This can be explained by examining the hysteresis curves from tests performed above a strain range of $0.3 \%$ (Fig. 8). During the monotonic loading, a stress peak is reached around a tensile strain of $0.15 \%$. Afterwards, the material softens. Hence, the monotonic softening can only be seen in tests performed at strain ranges of $0.6 \%$ and $1.0 \%$ but not at $0.3 \%$.

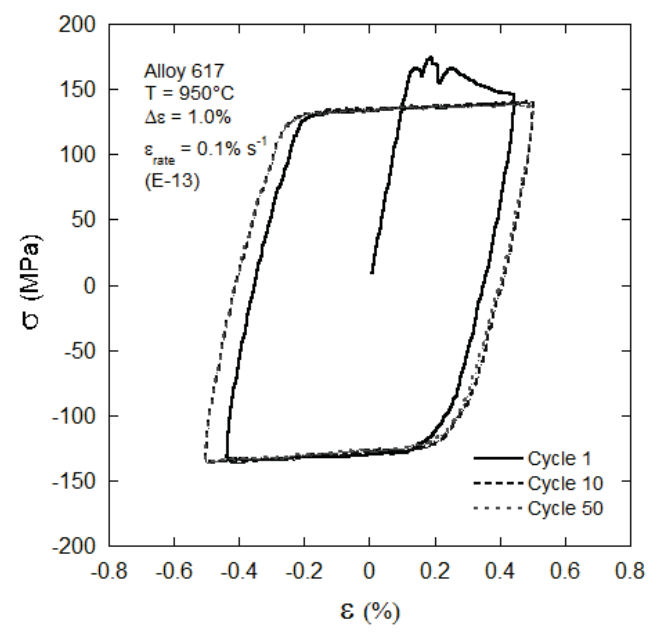

Fig. 8 Alloy 617 hysteresis loops from a UF1 test performed at $950^{\circ} \mathrm{C}$

The hysteretic response is further complicated by a behavior seen in tests performed at a strain range of $0.3 \%$. The hysteretic loop shapes in tests performed without a hold are vastly different than the loop shapes observed with a hold (compare Figs. 9 and 10). In addition, note the mid-strain stress peak seen in the hysteresis response after the tension hold in Fig. 10. This phenomenon appears in all tests performed at $950^{\circ} \mathrm{C}$ with tension holds; this is discussed in further detail in [6].

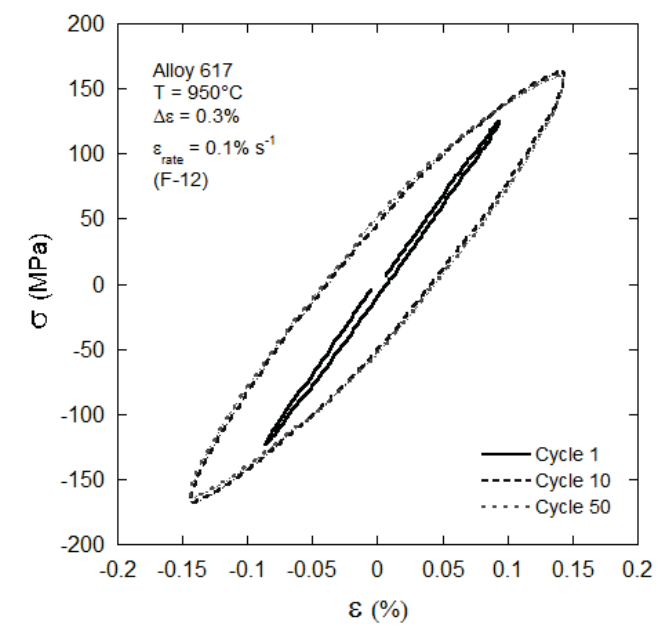

Fig. 9 Alloy 617 hysteresis loops from a UF1 test performed at $950^{\circ} \mathrm{C}$

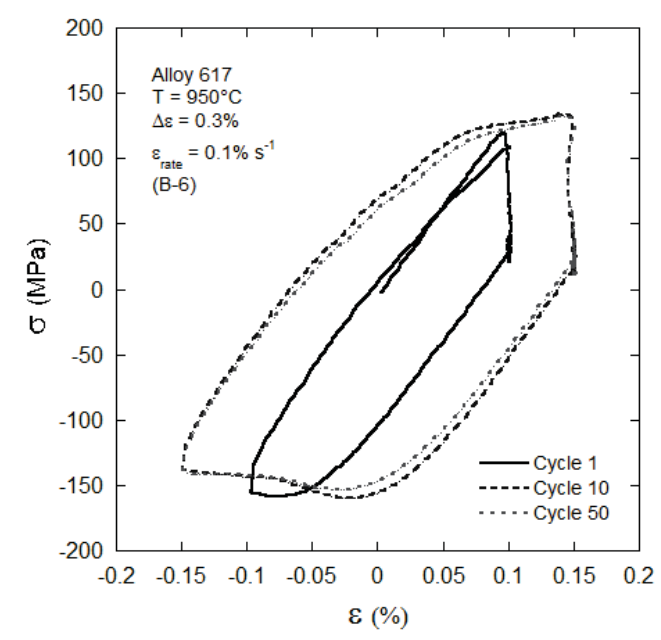

Fig. 10 Alloy 617 hysteresis loops from a UF2 test performed at $950^{\circ} \mathrm{C}$

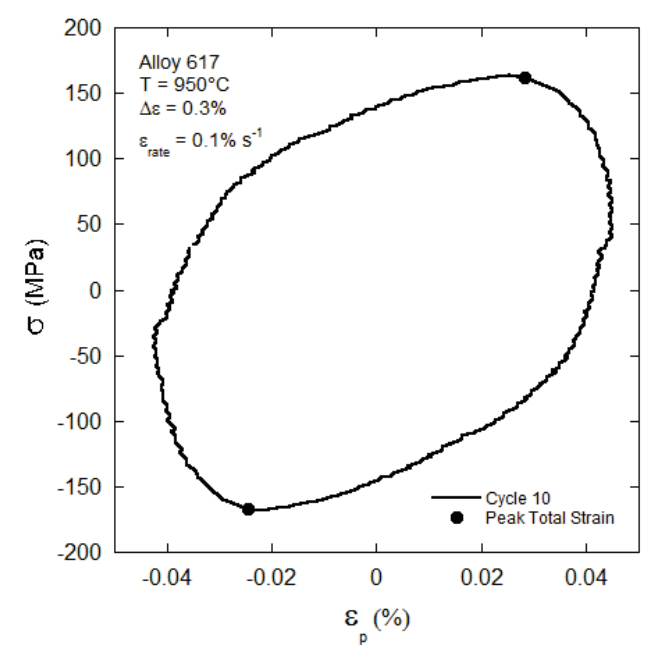

Fig. 11 Alloy 617 hysteresis loops in plastic strain space from a $\mathrm{UF} 1$ test performed at $950^{\circ} \mathrm{C}$ 
Lastly, another interesting phenomenon can be seen in Fig. 11, the plastic strain vs. stress curve of the test shown in Fig. 9. Upon unloading, for a short period, the total strain increment is negative, yet the plastic strain increment is positive. This phenomenon is not intuitive, but is induced by the viscosity (creep) of the material at high temperatures.

\section{Ratcheting Experiments}

Ratcheting is a phenomenon in which the cyclic peak strain is gradually increased under cyclic stress-controlled loading with a significant mean stress (see Figs. 12-13). Ratchetingcreep is a combination of the ratcheting and creep responses. In this case, a tension hold has been applied to a stress-controlled load history to achieve the responses seen in Figs. 14-15.

Eleven uniaxial ratcheting tests have been performed so far and 16 more test are underway. Two main comparisons can be drawn from the current set of ratcheting data: one, the rate of strain ratcheting and two, the similarities and differences in hysteresis loop shapes. In Figs. 16 and 17, the strain at peak tensile stress $\left(\varepsilon_{\text {peak }}\right)$ is plotted against number of cycles $(\mathrm{N})$. In Fig. 16 the rate of strain ratcheting of the UR1 test, with a lower minimum stress, is the same as the rate of strain ratcheting of the UR3 test, with a zero minimum stress. This phenomenon is also seen is Fig. 17 for UR2 and UR4 tests with a maximum stress of $70 \mathrm{MPa}$. However, the UR2 test with a maximum stress of $50 \mathrm{MPa}$ in Fig. 17 has a much lower rate of strain ratcheting than the UR4 with the same peak stress. In every stress-controlled test performed with a tension hold, the rate of strain accumulation was governed primarily by the rate of creep. Consequently, the UR2 test with a maximum stress of $50 \mathrm{MPa}$ had a lower rate of creep than the UR4 test with the same peak stress. The reason behind this significantly lower rate of creep is not currently understood. It is noted here that the fatigue life is not indicated by the last data point shown in Figs. 16 and 17. In fact, failure in any of the ratcheting and ratcheting-creep tests could not be obtained within a strain of $10 \%$, the maximum strain the extensometer could record. Hence, the tests were stopped upon reaching a strain of $10 \%$. Additionally, the peak strains reached in monotonic tensile tests at $850^{\circ} \mathrm{C}$ and $950^{\circ} \mathrm{C}$ are greater than $60 \%$. This suggests that it could be possible for much larger strain to be reached if these tests were continued with the ability to record larger strains.

Figures 12-15, show close-ups of the hysteretic response of UR3 and UR4 test performed at both 850 and $950^{\circ} \mathrm{C}$. UR1 and UR2 tests are not shown because they show similar responses to that of the UR3 and UR4 tests. As can be seen in Figs. 12 and 13, the shape of the hysteretic response to the UR3 loading path at both 850 and 950 are similar in nature. The magnitude of the load applied and the rate of strain ratcheting are the only noticeable differences. Note that in Fig. 12, the first few cycles were left out. To achieve a peak stress of $230 \mathrm{MPa}$ at $850^{\circ} \mathrm{C}$ some degree of strain hardening must be achieved. Therefore, the first few cycles showed an atypical amount of strain accumulation than would otherwise be seen throughout the rest of the test. One intriguing aspect of the hysteretic response in these two figures is the nature of the response during unloading. For a brief period after unloading, there is still an accumulation of strain. This is more noticeable in the tests performed with higher peak stresses. This feature may be attributed to the viscous (creep) behavior of alloy 617 at high temperatures.

As can be seen in Figs. 14 and 15, strain ratcheting under the UR4 loading path is due primarily to creep at both $850^{\circ} \mathrm{C}$ and $950^{\circ} \mathrm{C}$.

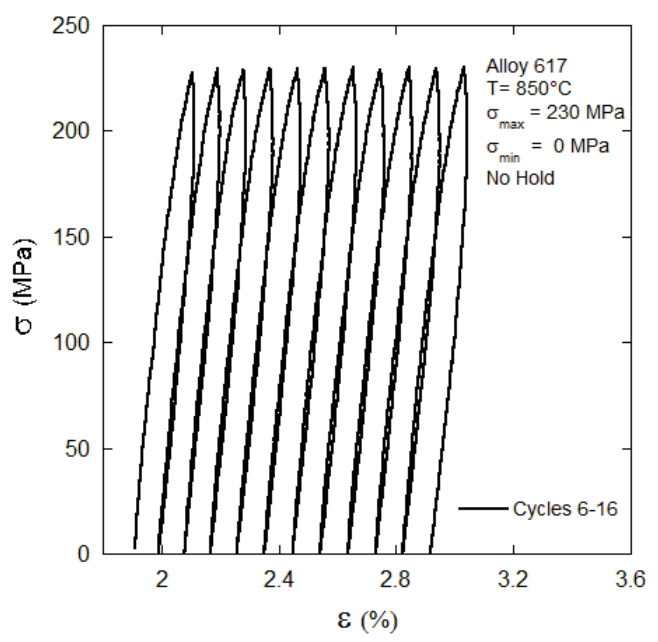

Fig. 12 Alloy 617 hysteresis loops from a UR3 test performed at $850^{\circ} \mathrm{C}$

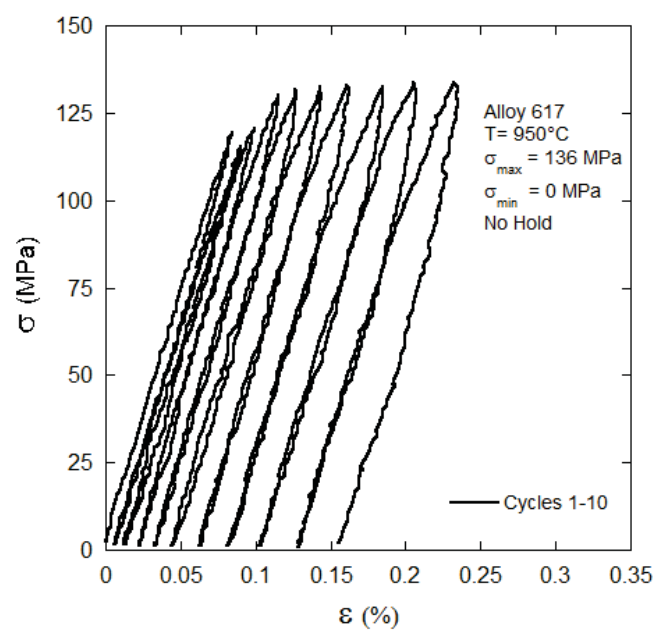

Fig. 13 Alloy 617 hysteresis loops from a UR3 test performed at $950^{\circ} \mathrm{C}$ 


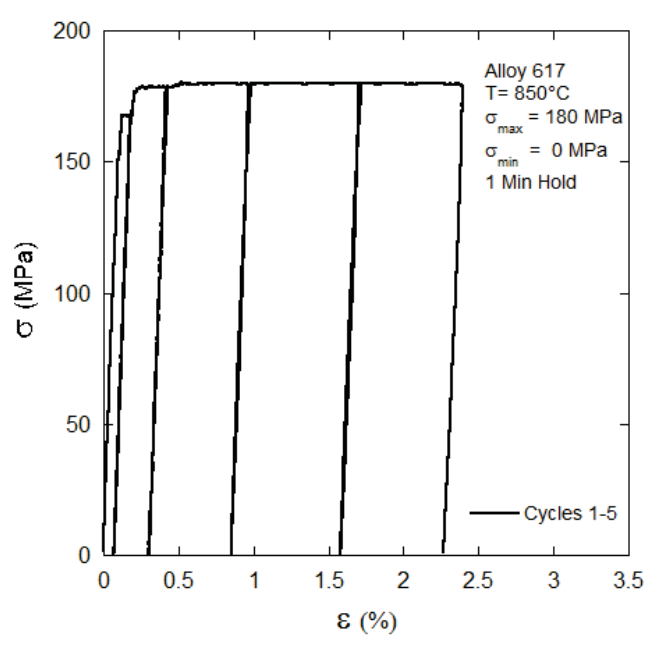

Fig. 14 Alloy 617 hysteresis loops from a UR4 test performed at $850^{\circ} \mathrm{C}$

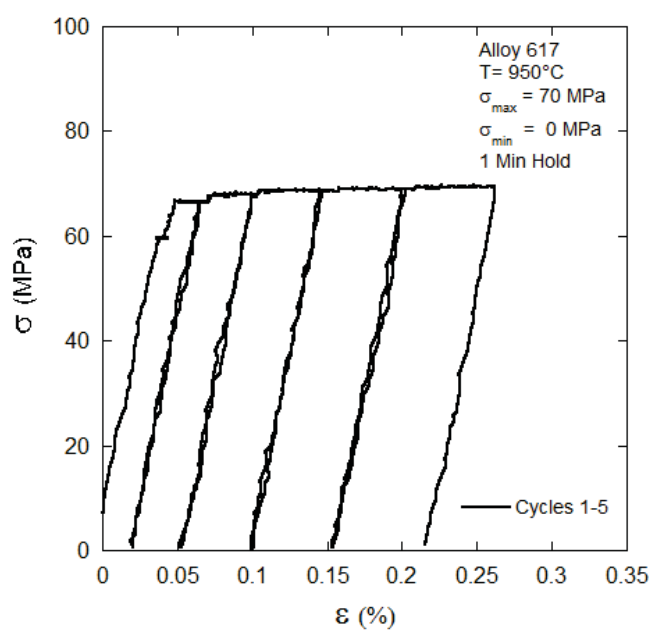

Fig. 15 Alloy 617 hysteresis loops from a UR4 test performed at $950^{\circ} \mathrm{C}$

\section{Constitutive Model}

\section{Main Constitutive Equations}

The unified constitutive model used in this investigation is an extension of the Chaboche viscoplastic model presented in [9-10]. The decomposition of strain into elastic and viscoplastic portions follows the additive strain decomposition rule. Where, $\varepsilon^{\mathrm{e}}$ is the elastic strain and $\varepsilon^{\mathrm{in}}$ is the inelastic strain.

The elastic strain is governed by the generalized Hooke's law.

$$
\boldsymbol{\varepsilon}^{e}=\frac{1+v}{E} \boldsymbol{\sigma}-\frac{v}{E}(t r \boldsymbol{\sigma}) \mathbf{I}
$$

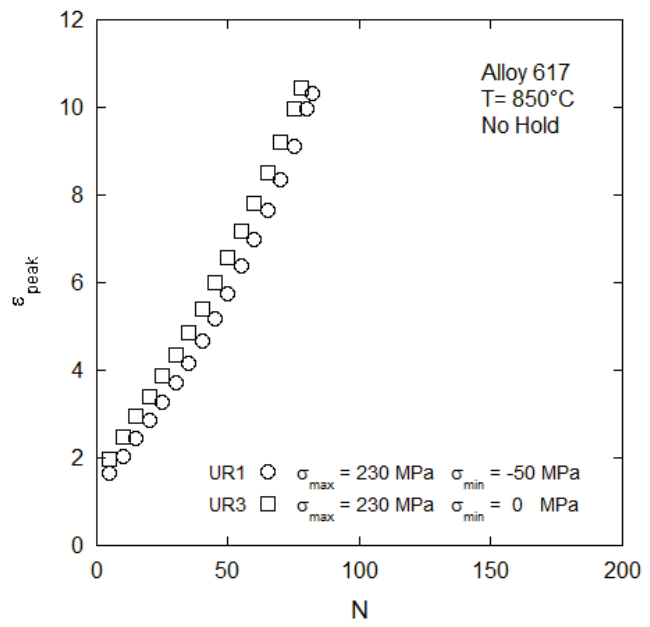

Fig. 16 Peak cycle strain $\left(\varepsilon_{\text {peak }}\right)$ vs. cycles $(N)$ in UR1 and UR3 experiments performed at $850^{\circ} \mathrm{C}$

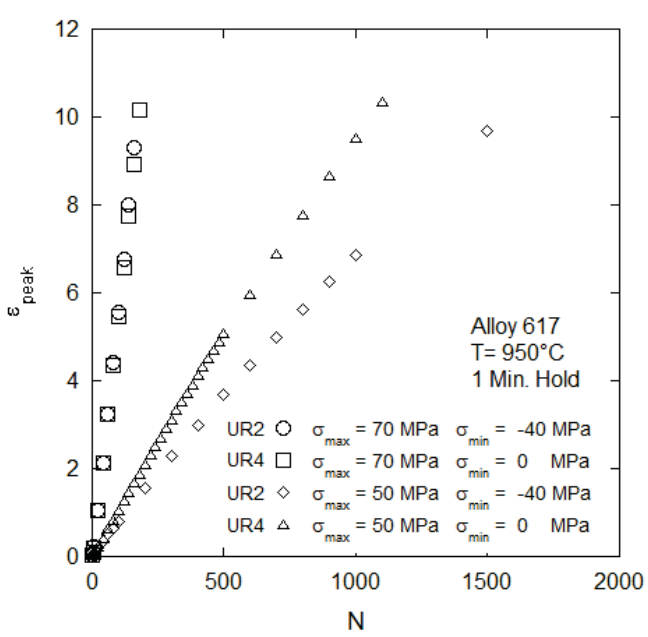

Fig. 17 Peak cycle strain $\left(\varepsilon_{\text {peak }}\right)$ vs. cycles (N) in UR2 and UR4 experiments performed at $950^{\circ} \mathrm{C}$

Where, E and $v$ represent the elastic modulus and Poisson's ratio, respectively. $\boldsymbol{\sigma}$ and $\mathbf{I}$ are the stress tensor and the identity matrix. Lastly, tr is the trace of $\boldsymbol{\sigma}$.

The yield surface is represented by the von-Mises yield criterion.

$$
\begin{aligned}
& f(\boldsymbol{\sigma}-\boldsymbol{\alpha})=\sqrt{\frac{3}{2}(\boldsymbol{s}-\boldsymbol{a}):(\boldsymbol{s}-\boldsymbol{a})} \\
& -\left(\sigma_{o}+R(p)\right)
\end{aligned}
$$


Where, $\boldsymbol{\alpha}$ is the back stress tensor, $\mathbf{s}$ and a are the deviators of the stress and back stress tensors, respectively, and $\sigma_{o}$ and $R(p)$ are the initial yield stress and the degree of isotropic hardening as a function of accumulated plastic strain.

The flow rule adopted allows for rate dependent behavior to be accounted for. This is of critical importance when modeling high temperature materials which behave as viscoplastic solids. This functionality comes directly from the definition of $\dot{p}$, the rate of plastic strain accumulation. This is based on Norton's power law, which relates the secondary creep rate to the applied stress. In this analogy, the overstress, or the distance from the current stress state to the yield surface, is analogous to the stress applied in creep. Furthermore, the total inelastic strain rate is analogous to the creep strain rate (see equations 4 and 5).

$$
\begin{aligned}
& \dot{\boldsymbol{\varepsilon}}^{i n}=\frac{3}{2} \dot{p} \frac{\boldsymbol{s}-\boldsymbol{a}}{J(\boldsymbol{\sigma}-\boldsymbol{\alpha})} \\
& \dot{p}=\left\langle\frac{J(\boldsymbol{\sigma}-\boldsymbol{\alpha})-R(p)-\sigma_{o}}{K}\right\rangle^{n} \\
& J(\boldsymbol{\sigma}-\boldsymbol{\alpha})=\sqrt{\frac{3}{2}(\boldsymbol{s}-\boldsymbol{a}):(\boldsymbol{s}-\boldsymbol{a})}
\end{aligned}
$$

The Chaboche kinematic hardening rule is used with four back stresses [9-10]. The rule has a linear hardening, dynamic recovery, and static recovery terms. While the linear hardening and dynamic recovery term govern the overall hysteresis loop shape, the static recovery term allows for stress relaxation to be simulated during strain holds.

$\dot{\boldsymbol{a}}=\sum_{i=1}^{4} \dot{\boldsymbol{a}}_{i}$

$\dot{\boldsymbol{a}}_{i}=\frac{2}{3} C_{i} \dot{\boldsymbol{\varepsilon}}^{v p}-\gamma_{i} \boldsymbol{a}_{i} \dot{p}-b_{i} J\left(\boldsymbol{\alpha}_{i}\right)^{r_{i}-1} \boldsymbol{a}_{i}$

It is well documented both in this investigation and in previous works that the shape of hysteresis loops can vary dramatically with changes in strain range $[9-10,12]$. While the preceding equations are able to model each strain range well independently, they require different model parameters for each strain range. However, to be able to simulate material responses well in a finite element program requires a unified constitutive model which is able to simulate all strain ranges without manually changing the model parameters. To implement such a scheme, a plastic strain memory surface has been implemented to keep track of the current plastic strain range. This is achieved through the incorporation a plastic strain memory surface as suggested in $[9,11]$.

The following equations represent the strain memory surface:

$$
\begin{aligned}
g= & \sqrt{\frac{2}{3}\left(\boldsymbol{\varepsilon}^{i n}-\mathbf{Y}\right):\left(\boldsymbol{\varepsilon}^{i n}-\mathbf{Y}\right)}-q \leq 0 \\
\dot{q}= & {\left[\eta H(g)\left\langle\boldsymbol{n}: \boldsymbol{n}^{*}\right\rangle\right.} \\
& \left.-\xi(1-H(g)) q^{m}\right] \dot{p} \\
\dot{Y}= & \sqrt{\frac{3}{2}}\left[(1-\eta) H(g)\left\langle\boldsymbol{n}: \boldsymbol{n}^{*}\right\rangle \boldsymbol{n}^{*}\right. \\
& \left.-\xi(1-H(g)) \boldsymbol{n}^{*} q^{m}\right] \dot{p} \\
\mathbf{n}= & \sqrt{\frac{3}{2}} \frac{\boldsymbol{s}-\boldsymbol{a}}{J(\boldsymbol{\sigma}-\boldsymbol{\alpha})} \\
\mathbf{n}^{*}= & \sqrt{\frac{2}{3}} \frac{\boldsymbol{\varepsilon}^{i n}-\mathbf{Y}}{g\left(\boldsymbol{\varepsilon}^{i n}-\mathbf{Y}\right)}
\end{aligned}
$$

Equation (9) represents the plastic strain memory surface, similar in form to the von-Mises yield surface, where $\varepsilon^{\text {in }}$ is the current plastic strain, $\mathbf{Y}$ is the center of the surface in plastic strain space and $q$ is the size of the surface. The variables $q$ and $\mathbf{Y}$ are updated by the evolution equations (10) and (11). Here, $\eta$ governs the isotropic expansion of the surface while, (1-n), governs the kinematic movement of the surface. $\mathrm{H}(\mathrm{g})$ is the Heaviside function. This allows for a slow contraction of the surface when the plastic strain state exists inside the surface. This contraction is governed by the parameters $\xi$ and $\mathrm{m}$.

To implement strain range dependence, equations governing the change of key parameters are necessary. These equations are a function of the strain memory surface size q, which approximately represents the current plastic strain amplitude, or half the plastic strain range, of the simulation. Currently, the parameters that are dependent on the strain memory surface size are: the kinematic hardening parameters $\mathrm{C}_{\mathrm{i}}$ and $\gamma_{\mathrm{i}}$, the isotropic hardening variable $\mathrm{R}$, and the rate dependence parameter $\mathrm{K}$. The following are the current set of equations that govern the update of these parameters.

$$
\begin{aligned}
& R_{s}(q)=a_{1 R}\left(1-e^{-b_{1 R}\left(q-c_{1 R}\right)}\right) \\
& \dot{\gamma}_{i}=D_{\gamma i}\left(\gamma_{i}^{A S}(q)-\gamma_{i}\right) \dot{p} \\
& \gamma_{i}^{A S}(q)=a_{\gamma i}+b_{\gamma i} e^{-c_{\gamma i} q} \\
& \dot{C}_{i}=D_{C i}\left(C_{i}^{A S}(q)-C_{i}\right) \dot{p} \\
& C_{i}^{A S}(q)=a_{C i}+b_{C i} e^{-c_{C i} q}
\end{aligned}
$$




\section{Simulations}

The constitutive model used in this study has the ability to simulate a wide range of material responses. Currently, two sets of material parameters have been determined; one to represent the material response at $850^{\circ} \mathrm{C}$ and another to represent the response at $950^{\circ} \mathrm{C}$ (see table 2). The model simulations for a UF1 loading path performed at a temperature of $850^{\circ} \mathrm{C}$, a strain range of $0.6 \%$, and a strain rate of $0.1 \% / \mathrm{s}$ can be seen in Figs. $18-20$. As can be seen in these three figures the model is able to simulate the hardening response quite well throughout the cycle life of the material.

\begin{tabular}{|c|c|c|c|c|c|}
\hline \multicolumn{6}{|c|}{ Table 2: Model Parameters } \\
\hline \multicolumn{2}{|c|}{ Parameter } & \multicolumn{2}{|c|}{$850^{\circ} \mathrm{C}$} & \multicolumn{2}{|c|}{$950^{\circ} \mathrm{C}$} \\
\hline \multicolumn{2}{|c|}{$E(\mathrm{MPa})$} & \multicolumn{2}{|c|}{157100} & \multicolumn{2}{|c|}{140000} \\
\hline \multicolumn{2}{|c|}{$\sigma_{0}(\mathrm{MPa})$} & \multicolumn{2}{|c|}{103.6} & \multicolumn{2}{|c|}{0} \\
\hline \multicolumn{2}{|c|}{$K$} & \multicolumn{2}{|c|}{1000000} & \multicolumn{2}{|c|}{500} \\
\hline \multicolumn{2}{|c|}{$n$} & \multicolumn{2}{|c|}{0.0000001} & \multicolumn{2}{|c|}{2.379} \\
\hline \multicolumn{2}{|c|}{$C_{l}(\mathrm{MPa})$} & \multicolumn{2}{|c|}{1088366} & \multicolumn{2}{|c|}{134552001} \\
\hline \multicolumn{2}{|c|}{$C_{2}(\mathrm{MPa})$} & \multicolumn{2}{|c|}{432543} & \multicolumn{2}{|c|}{134552001} \\
\hline \multicolumn{2}{|c|}{$C_{3}(\mathrm{MPa})$} & \multicolumn{2}{|c|}{46938} & \multicolumn{2}{|c|}{361429} \\
\hline \multicolumn{2}{|c|}{$C_{4}(\mathrm{MPa})$} & \multicolumn{2}{|c|}{13957} & \multicolumn{2}{|c|}{2000} \\
\hline \multicolumn{2}{|c|}{$\gamma_{1}$} & \multicolumn{2}{|c|}{31415} & \multicolumn{2}{|c|}{12273715} \\
\hline \multicolumn{2}{|c|}{$\gamma_{2}$} & \multicolumn{2}{|c|}{31288} & 122 & 715 \\
\hline & & & & & \\
\hline & & & & & \\
\hline$D_{\gamma 1}$ & $\gamma_{1}^{o}$ & 46.3 & 18312 & - & - \\
\hline$D_{\gamma 2}$ & $\gamma_{2}^{o}$ & 46.1 & 18312 & - & - \\
\hline$D_{\gamma 3}$ & $\gamma_{3}^{o}$ & 4.65 & 1177 & - & - \\
\hline$D_{\gamma 4}$ & $\gamma_{4}^{o}$ & 0 & 480 & & \\
\hline & & - & - & & \\
\hline & & - & - & & \\
\hline & & & & & 354 \\
\hline & & & & 5.9 & $\mathrm{E}-06$ \\
\hline & & & & & \\
\hline & & & & & \\
\hline & & & & & \\
\hline & & & & & \\
\hline
\end{tabular}

Moving onto the model simulations at $950^{\circ} \mathrm{C}$, the current set of parameters for this temperature were developed to show the ability of the model to simulate rate dependence, relaxation, and the typical strain-controlled response. Currently, cyclic softening is not implemented at $950^{\circ} \mathrm{C}$. Therefore, a typical cycle was chosen that represents the material response in the first few cycles. In Figs. 21 - 23 it is shown that the model can simulate three different load paths quit well with one set of model parameters. Figure 21 shows the material response to the UF1 loading path with a strain rate of $0.1 \% / \mathrm{s}$. Figure 22 shows the material response to a UF2 loading path with a strain rage of $0.1 \%$ s. Finally, Fig. 23, shows the material response to a UF1 loading path performed at a strain range of $0.04 \% / \mathrm{s}$.

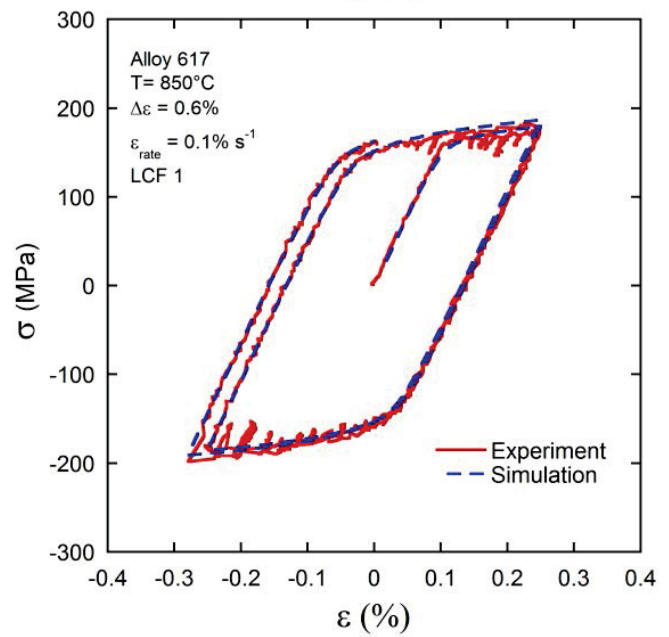

Fig. 18: Simulation of the first cycle of a UF1 test performed at $850^{\circ} \mathrm{C}$

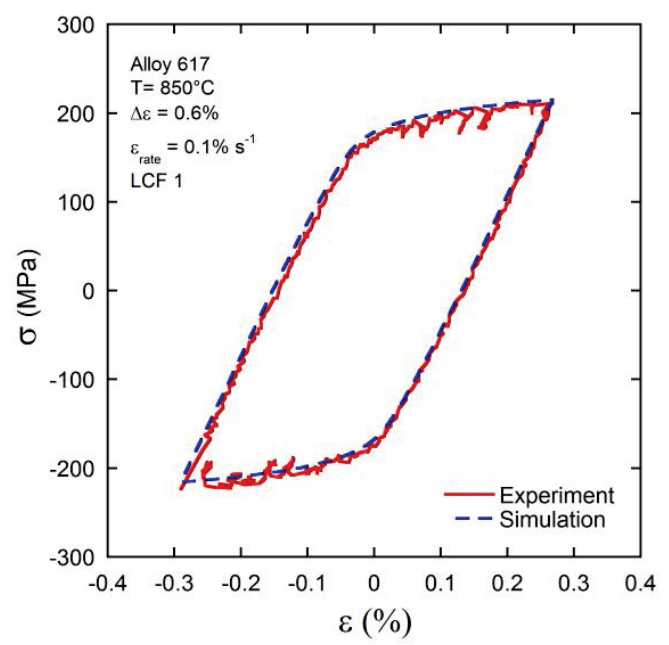

Fig. 19: Simulation of the tenth cycle of a UF1 test performed at $850^{\circ} \mathrm{C}$ 


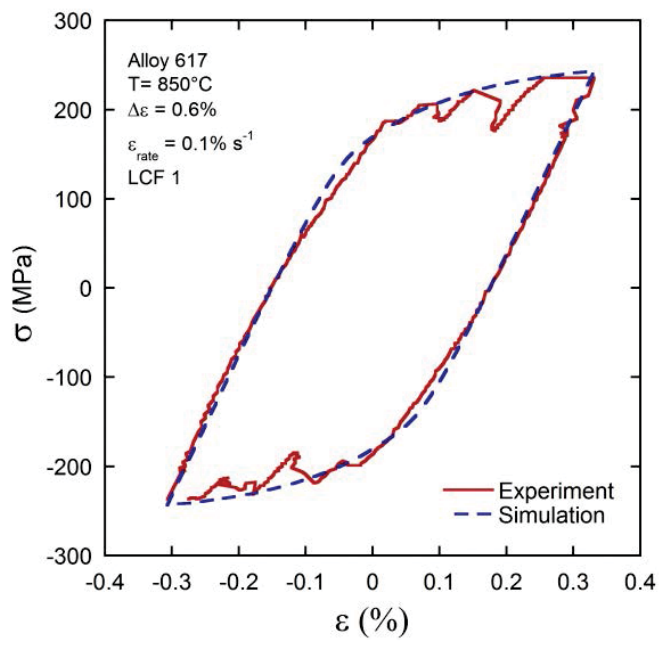

Fig. 20: Simulation of the tenth cycle of a UF1 test performed at $850^{\circ} \mathrm{C}$

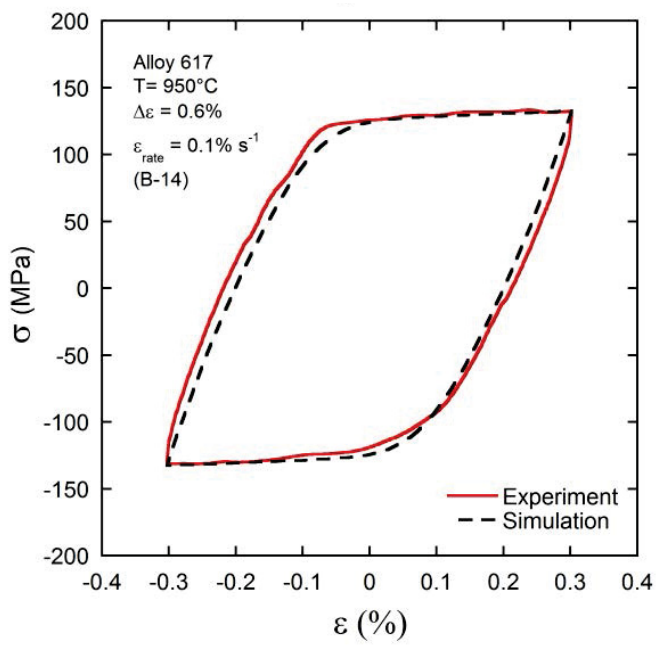

Fig. 21 Simulation of the ninth cycle of a UF1 test performed at $950^{\circ} \mathrm{C}$

\section{Conclusion}

A broad set of fatigue, fatigue-creep, ratcheting, and ratcheting creep experiments are underway. The material responses observed from these tests have been discussed and it has been shown that there are a wide variety of phenomena that exist at the elevated temperatures of $850^{\circ} \mathrm{C}$ and $950^{\circ}$ that must be accounted for in constitutive modeling. It has also been shown that the unified constitutive model used in this study has the ability to simulate a wide variety of high temperature fatigue responses, such as, rate dependence, stress relaxation, and cyclic hardening. However, developing a unified set of material parameter is still underway. Lastly, the ability of the unified constitutive model to predict ratcheting responses is still being investigated.

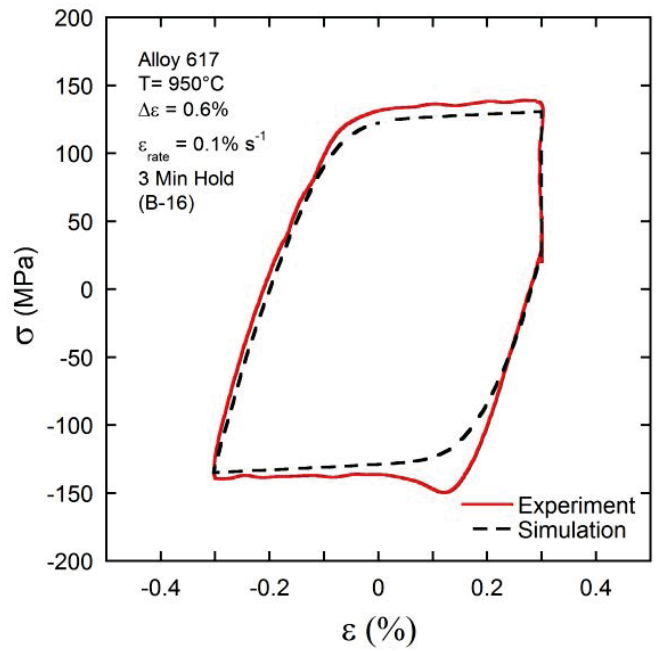

Fig. 22 Simulation of the eighth cycle of a UF2 test performed at $950^{\circ} \mathrm{C}$

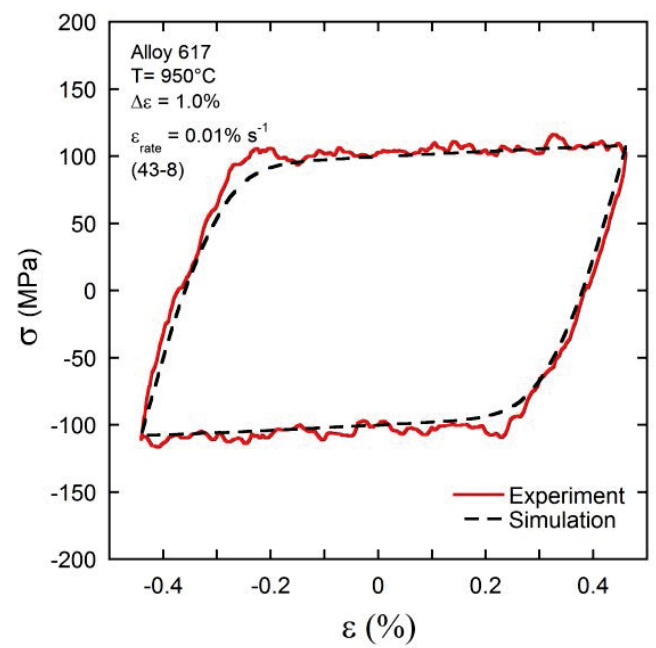

Fig. 23 Simulation of the second cycle of a UF1 test performed at $950^{\circ} \mathrm{C}$

\section{Acknowledgements}

This research is being performed using funding received from the DOE Office of Nuclear Energy's Nuclear Energy University Programs.

\section{Copyright Notice}

This manuscript has been authored by Battelle Energy Alliance, LLC under Contract No. DE-AC07-05ID14517 with the U.S. Department of Energy. The United States Government retains and the publisher, by accepting the article for publication, acknowledges that the United States Government retains a nonexclusive, paid-up, irrevocable, world-wide license to publish or reproduce the published form of this manuscript, or allow others to do so, for United States Government purposes. 


\section{References}

1. Carroll, L., Madland, R., and Wright, R., 2011, "Creepfatigue of High Temperature Materials for VHTR: Effect of Cyclic Loading and Environment," Paper 11284, Proceedings of ICAPP 2011, Nice, France.

2. Carroll, L.J, Cabet, C., Madland, R., and Wright, R.N., 2011, "Creep and Environmental Effects on the High Temperature Creep-Fatigue Behavior of Alloy 617', Journal of ASTM International, Vol. 8, No. 6

3. Carroll, L., Cabet, C., and Wright, R., 2010, "The Role of Environment on High Temperature Creep-Fatigue Behavior of Alloy 617," PVP2010-26126, ASME 2010 Pressure

4. Wright, J.K., Carroll, L.J., Cabet, C., Lillo, T.M., Benz, J.K., Simpson, J.A., Lloyd, W.R., Chapman, J.A., and Wright, R.N., 2012, "Characterization of Elevated Temperature Properties of Heat Exchanger and Steam Generator Alloys," Nuclear Engineering and Design, 251, pp. 252-260.

5. Carroll, L.J., Cabet, C., Carroll, M.C., and Wright, R.N., 2013, "The Development of Microstructural Damage during High Temperature Creep-Fatigue of a Nickel Alloy", International Journal of Fatigue, 47, pp. 115-125.

6. Carroll, M.C. and Carroll, L.J., Developing Dislocation Subgrain Structures and Cyclic Softening During High Temperature Creep-Fatigue of a Nickel Alloy, Accepted for publication in Met. Trans.

7. Rao, K.B.S, Meurer, H.P., Schuster, H., 1988, “CreepFatigue Interaction of Incontel 617 at $950^{\circ} \mathrm{C}$ in Simulated Nuclear Reactor Helium," Materials Science and Engineering, A104, pp. 37-51

8. Rao, K.B.S, Schiffers, H., Schuster, H., and Nickel, H., 1988, "Influence of Time and Temperature Dependent Processes on Strain Controlled Low Cycle Fatigue Behavior of Alloy 617," Metallurgical Transactions A, 19A, pp. 359-371.

9. Chaboche, J. L., 1989, "Constitutive Equations for Cyclic Plasticity and Cyclic Viscoplasticity," International Journal of Plasticity, 5(3) pp. 247-302.

10. Chaboche, J. L., 2008, "A Review of some Plasticity and Viscoplasticity Constitutive Theories," International Journal of Plasticity, 24(10) pp. 1642-1693.

11. Nouailhas, D., Cailletaud, G., Policella, H., 1985, "On the Description of Cyclic Hardening and Initial Cold Working," Engineering Fracture Mechanics, 21(4) pp. 887895.

12. Krishna, S., Hassan, T., Ben Naceur, I., 2009, "Macro Versus Micro-Scale Constitutive Models in Simulating Proportional and Nonproportional Cyclic and Ratcheting Responses of Stainless Steel 304," International Journal of Plasticity, 25(10) pp. 1910-1949. 